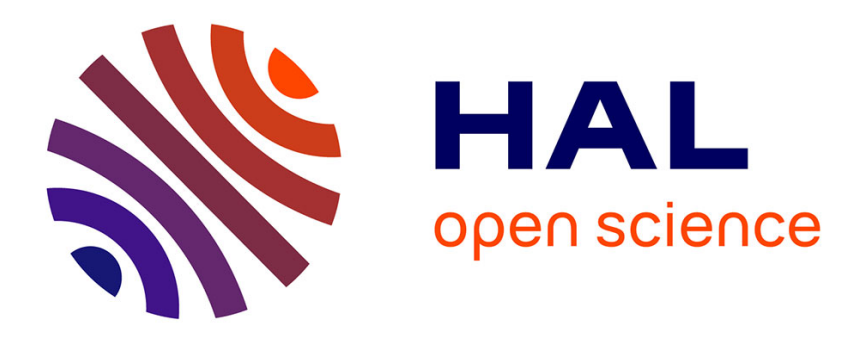

\title{
Understanding preference for egalitarian policies in health: Are age and sex determinants?
}

\author{
Ignacio Abásolo, Aki Tsuchiya
}

\section{To cite this version:}

Ignacio Abásolo, Aki Tsuchiya. Understanding preference for egalitarian policies in health: Are age and sex determinants?. Applied Economics, 2008, 40 (19), pp.2451-2461. 10.1080/00036840600993940 . hal-00581979

\section{HAL Id: hal-00581979 \\ https://hal.science/hal-00581979}

Submitted on 1 Apr 2011

HAL is a multi-disciplinary open access archive for the deposit and dissemination of scientific research documents, whether they are published or not. The documents may come from teaching and research institutions in France or abroad, or from public or private research centers.
L'archive ouverte pluridisciplinaire HAL, est destinée au dépôt et à la diffusion de documents scientifiques de niveau recherche, publiés ou non, émanant des établissements d'enseignement et de recherche français ou étrangers, des laboratoires publics ou privés. 


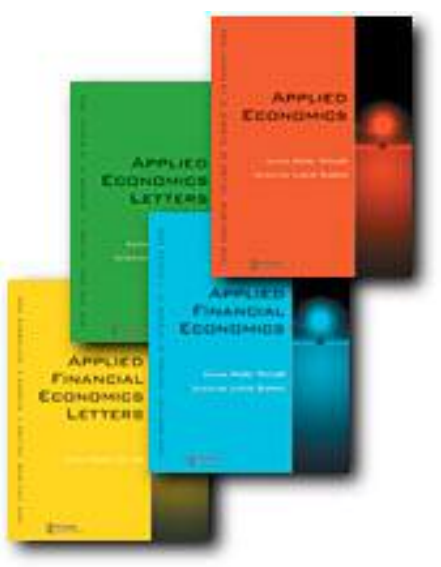

Understanding preference for egalitarian policies in health: Are age and sex determinants?

\begin{tabular}{|r|l|}
\hline Journal: & Applied Economics \\
\hline Manuscript ID: & APE-05-0467.R1 \\
\hline Journal Selection: & Applied Economics \\
\hline JEL Code: & $\begin{array}{l}\text { I18 - Government Policy } \mid \text { Regulation } \mid \text { Public Health }<\text { I1 - Health < I } \\
\text { - Health, Education, and Welfare }\end{array}$ \\
\hline Keywords: & inequality in health, egalitarianism \\
\hline
\end{tabular}

Manuscript Central $^{\text {powers by ScholarOne }}$ 


\title{
UNDERSTANDING PREFERENCE FOR EGALITARIAN POLICIES IN HEALTH: ARE AGE AND SEX DETERMINANTS?
}

\author{
Ignacio Abásolo ${ }^{1}$, Aki Tsuchiya ${ }^{2}$ \\ ${ }^{1}$ Departamento de Economía de las Instituciones, Estadística Económica y Econometría, \\ Facultad de Ciencias Económicas y Empresariales. Universidad de La Laguna, Campus de \\ Guajara. La Laguna. Tenerife. Spain. \\ ${ }^{2}$ Department of Economics and School of Health and Related Research, University of \\ Sheffield, 30 Regent Street, Sheffield, S1 4DA,United Kingdom.
}

Running title: Preferences for egalitarian policies in health

\begin{abstract}
This paper presents an empirical assessment of the relevance of different factors when understanding preferences for outcome-egalitarian policies in health, in particular respondent age and sex. A representative sample of the Spanish population was interviewed $(n=1,209)$. After being informed that those from the higher social class have longer life expectancy at birth than those from the lower social class, respondents were required to choose between two programmes: to increase life expectancy of the two groups by the same amount (the "distribution neutral" programme); and to target the lowest social class group, thereby reducing current health inequalities (the "targeting" or "egalitarian" programme). Two variants, one with and the other without visual aid, are used. Majority (69\%) of respondents support targeting. An effect of age was observed, where younger and older individuals are less likely to target the egalitarian policy than those in middle age. However, individual's sex was not associated with targeting behaviour. In addition, right-wingers or/and individuals living in a high per capita income region are less likely to target. On the other hand, neither individual's education nor household income has a significant impact on targeting. Finally, regarding the two variants, results suggest that the visual aid is associated with less targeting.
\end{abstract}

\section{Corresponding author}

Ignacio Abásolo: Departamento de Economía de las Instituciones, Estadística Económica y Econometría, Facultad de Ciencias Económicas y Empresariales. Universidad de La Laguna, Campus de Guajara. La Laguna. Tenerife. Spain. Fax: 0034-922317204; $\quad$ Tel: 0034-922317088; e-mail:iabasolo@ull.es 


\section{INTRODUCTION}

Maximising average population health is a major objective of public health care systems. However, modern health care systems have another objective: equality in the distribution of health. Various studies have explored how members of the public see the balance between these two objectives (see for example Johannesson \& Gerdtham, 1996; Anderson \& Lyttkens, 1998; Cuadras-Morato et al. 2001; Dolan \& Robinson, 2001; Dolan et al, 2002; Abásolo \& Tsuchiya 2004). A common feature of most studies is that neither maximisation nor equalisation of health alone is supported. However, what has been rarely investigated so far is what makes some people more egalitarian than others in health, that is, what factors determine preferences for egalitarian policies in health. An exception is Lindholm et al (1997), which found that support for different interpretations of equity in health is strongly associated with the respondent's sex and political affiliation: women, and those who support political parties on the left have relatively more sympathies towards equity. Another related study is the one of Hudson and Jones (2002) that shows with UK data that self-interest attitudes (together with public-interest attitudes) have a significant effect on preferences related to redistributive policies in health. In addition, the impact of age and education is such that as people get older and/or more educated they are less averse to higher taxes for health policy purposes.

Studies on people's attitudes and motivations outside the health economics literature have looked at attitudes over income inequalities, collective action, or moral and political orientation in general. Mainstream economics literature has assumed that self-interested preferences play a strong role in determining individual's attitudes towards income inequalities, as a direct consequence of the standard economic public choice argument of the self-interested median voter hypothesis (Romer 1975, Meltzer \& Richards 1981). Bénabou \& Ok (2001) has shown using an intergenerational model how the preferences of those with below average income to oppose redistributive policies can be consistent with self interest, if they expect to raise above mean income in the future, or the "prospect of upward mobility (POUM)" hypothesis (also see Ohtake and Tomioka, 2004; Fong, 2001), which has implications for the effect of age on such preferences. In their studies of the determinants of charitable donations in Canada, Kitchen \& Dalton (1990) and Kitchen (1992), show that family wealth and age of the household tend to be significant determinants of charitable giving. 
In addition to age, and going beyond self-interest, the effect of gender in moral and political orientation has been subject of analysis in a number of empirical studies. Beutel \& Marini (1995) find that women are more likely than men to display group solidarity. Similarly, Davies (1983) shows that women display a greater ability to see things form the perspective of others. Gilligan (1993) shows that while men tend to base their moral arguments on concepts of justice and rights, women tend to appeal to notions of care and to a desire to minimise harm to others. However, Jaffee \& Hyde (2000) found evidence that do not offer support the claim that care orientation is used by women and justice orientation is used predominantly by men. Other researchers show that females support more policies like public protection, 'compassion' issues and traditional values (Shapiro \& Hanajan, 1986). Eckel \& Grossman (1998) in their exploration of basic gender differences in economic behaviour show that women are more socially-orientated (selfless) and men more individually-orientated (selfish).

Finally, another interesting point raised in the literature is that people may prefer more redistribution to the poor if they believe that poverty is caused by circumstances beyond individual control. This implies a social perspective on distributive justice rather than (only) self-motivated preferences (see for example Fong, 2001; Charness \& Rabin, 2002; Fehr \& Fischbacher, 2002).

The motivation of this paper is to explore what factors can help us to understand social preferences for egalitarian policies in health in particular respondent age and sex. In addition, we will consider other factors that we anticipate to be relevant. To account for possible self-interest we will consider household income and education as proxies to capture that potential effect. We will also consider other controls such ideology or region of residence. Finally, the effect of framing the same question on responses and its interaction with respondent characteristics are investigated. Results from a survey in Spain that includes questions on preferences to reduce inequalities in health are used for this analysis (see Abasolo et al. 2001).

First, respondents were informed of a current health inequality across socio-economic groups, namely, that men from the highest social class have a longer life expectancy at 
birth (75 years) than men from the lowest social class $(70 \text { years })^{1}$. Then, respondents were asked to choose between two health programmes with the same cost: programme A, that extends the life expectancy of both these population groups by two years each (the "distribution neutral" programme), and programme B, that targets the disadvantaged group and increases their life expectancy by four years. Since, by targeting all the benefits to the disadvantaged group, programme B will reduce the inequality by the same amount, we will refer to this as the "targeting programme" or the "egalitarian programme". The aim of the questionnaire was to tap into the preferences of the respondent as a citizen, comparing public policies addressing issues of inequality and distribution, as opposed to a consumer, purchasing insurance policies for their own benefit. The survey question continued to identify the strength of inequality aversion by subjecting those respondents who choose the egalitarian policy to explicit trade offs between efficiency and equality; however, the present paper concentrates on the first exercise alone, where it is assumed that both programmes are equally efficient. At the end of the survey, socio-economic, demographic and ideological information were gathered to serve as the explanatory variables. Two different ways of presenting the options were used (a Pictorial variant and a Verbal variant), with the aim of testing whether or not these two different devices to present the same information lead to the same results.

\section{THE MODEL AND ESTIMATION METHODS}

We specify a model that explains the probability of a given respondent to target the disadvantaged group, as defined above. An underlying (or latent) variable $\left(T^{*}\right)$ represents an individual's propensity to choose this policy. We anticipate that demographic, socioeconomic and ideological characteristics are associated with people's attitudes towards egalitarianism. With respect to the first, age (A) and gender (G) are considered. Secondly, since we are dealing with attitudes regarding socio-economic inequalities, we may expect there to be some pattern in the responses by respondents' socio-economic status; proxies used to explore this possibility are household income $(Y)$, education $(E)$, per capita income

\footnotetext{
${ }^{1}$ The data are based on those for England (Acheson, 1998). Available data on life expectancy at age 25 by education groups in Madrid and Barcelona show similar patterns (Borrel et al. 1999).
} 
of the region of residence $(R)$, and being in the labour market $(L)^{2}$. In general, it is expected that all these variables are negatively related with the propensity to support the egalitarian health policy. Thirdly, political affiliation, or ideology $(I)$, is also assumed to have a role in the model. After all, people's attitude towards egalitarianism is an ideological issue, which might be favoured more by a left wing person. Lastly, we include in the model another variable $(Q)$ representing the questionnaire variant. The question could be presented to the respondents with the aid of pictures $(\mathrm{P})$ or verbally with no visual aids $(\mathrm{V})$. The aim of this regressor in the model is to determine whether there are significant differences in the estimated probabilities depending on the way the question is asked.

Thus, the model can be written as:

$$
T_{i}^{*}=T(G i, A i, E i, Y i, L i, I i, R i, Q i)+\varepsilon i
$$

In model [eq.1], the $i$ subscripts represent individual respondents, and $\varepsilon$ i captures influences unobserved by the analyst, which we assume to have a standard normal distribution with zero mean and constant variance. In practice, $T^{*}$ is unobserved. Rather, we observe $T i$, which is a dummy variable representing whether or not the individual actually chooses the targeting policy; therefore it is the realization of a binomial process defined by:

$$
T i=1 \text { if }\left[T_{i}^{*}>0\right]
$$

So, if the individual's propensity to target is positive $\left(T_{i}^{*}>0\right) \mathrm{s} / \mathrm{he}$ will choose the egalitarian policy $(T i=1)$, and if otherwise $\left(T_{i}^{*} \leq 0\right) \mathrm{s} /$ he will not $(T i=0)$.

\footnotetext{
${ }^{2}$ An additional variable "social class" was also available in the data set. However it was not used in this study due to two reasons. Firstly, because the definition of social class is not explicitly given (the respondent is simply asked whether s/he belongs to high, middle-high, middle, middle-low or low social class). So there is no correspondence at all with social class I and V referred in the main question. Actually $60 \%$ selfreported to belong to middle social class. Secondly, there is no correlation between the "social class" variable and other variables representative of socio-economic status such as education or family income.
} 
In order to select the functional form of the empirical model, socio-economic and statistical criteria are used. This has allowed us to consider the definitions of the set of dummy variables and whether the only continuous variable (age) enters the model in natural units, as logarithms or as higher-order powers. Interactions between regressors are also included and tested in the model. In particular, in order to test whether the mode of presenting the question $(P$ or $V$ ) has a different effect on the propensity to target across the different background characteristics specified in the model, we will test the joint hypothesis that the interactions of $Q$ with the rest of regressors are not significantly different from zero.

The estimation process will be undertaken through non-linear probit regressions. Likelihood ratio (LR) tests and Reset specification tests will be carried out to appraise the appropriateness of the different functional forms. Throughout, a 5\% significance level is used.

Estimations of model [eq.1] will allow us to empirically assess the relevance of the different hypothesised explanatory variables and appraise whether the way in which the question is formulated does not account or it does, and if it does in which way.

Model [eq.1] may be subject to selection bias due to incomplete survey data. In surveys of this sort respondents do not always provide answers to all the questions of the survey. It is the so-called "item non-response". If the pattern of non-response is not at random, conventional estimators may be biased and inconsistent. Tests for selection bias and correction, if necessary, are undertaken estimating a probit with sample selection (Greene 1997). The probit with sample selection works in a manner very similar to the Heckman model except that the response variable is binary. This method requires additional exogenous variables (or identifying variables), which should explain the probability of participating but have no direct impact on the probability to target.

So, let us assume an underlying (unobserved) variable $Y_{i}^{*}$ that determines selection into participating groups, i.e. $Y i=1$ when $Y_{i}^{*}>$ threshold, and $Y i=0$ when $Y_{i}^{*} \leq$ threshold. $Y_{i}^{*}$ would represent the inclination for the individual to participate answering all the relevant 
questions being $Y_{i}^{*}$ a linear function of some of the exogenous variables in model [eq.1] as well as some identifying variables as follows:

$$
Y_{i}^{*}=Y(G i, A i, L i, R i, M i, H i)+u i
$$

The identifying variables include $M i$, which represents the marital status of the individual (married, single, divorced or widow), and $\mathrm{Hi}$, which represents whether the individual lives in a rural area. The main criteria used here for proposing both set of identifying variables are that the variables have an impact on the probability to participate but are unrelated to the individual's preference for egalitarian policies. $u i$ is a random error term normally distributed with zero mean and constant variance.

Selection bias occurs when there is correlation between $Y$ and $\varepsilon$ (and therefore between $\varepsilon$ and $\boldsymbol{u}$ ); that is, when unobservable factors that influence the potentially selection are also influencing the probability to target. If so, selection bias will be corrected. To check whether selection bias is absent we will test, firstly, whether $\rho$ (the correlation of residuals) is significantly different from zero: if the covariance between $\varepsilon$ and $\boldsymbol{u}$ is significantly different from zero, then we cannot reject that there is no selection bias. In addition, a comparison of the estimates of both the initial probit and the probit with selection is undertaken: a large change in the coefficients, a change of the sign of the coefficients or a change in the statistical significance of the coefficients between the initial probit and the probit with selection indicate the existence of selection bias.

\section{DATA AND VARIABLES DEFINITION}

The data were collected during 1999 in Spain. A survey of 1,209 individuals over 18 years of age was undertaken. Face to face interviews were assigned across the 17 "Comunidades Autónomas" ("Regions" for short), reflecting the local resident population proportionally. Within each of the Regions, interviews were randomly allocated so that the achieved sample will be representative of the general Spanish population in terms of sociodemographic characteristics. Each of the two variants of the questionnaire was 
administered to approximately the same number of respondents: 602 for the P-variant and 607 for the V-variant. In terms of background characteristics, the distribution of these variables across the two variants is not statistically significantly different from each other.

The binary dependent variable, target, takes the value 1 if individual $i$ targets the worse off group, 0 if otherwise. Age is a continuous variable, which takes values between 18 and 94, and also enters the equation in quadratics. The binary variable female indicates whether the individual is female or male. Education is recorded by level of schooling and has been categorised in three dummy variables representing low education lowedu (those with primary school education or less), middle education midedu (those with secondary school education, the baseline category), and high education highedu (those with higher and university education). Household income is also categorised in three dummies high income (more than 1,653 euros per month), middle income (between 600 and 1,653 euros per month, the baseline category) and low income (less than 600 euros per month) ${ }^{3}$. Per capita income in the region of residence is captured by three dummies: high income regions highreg (those resident in Madrid, Navarra or País Vasco), low income regions lowreg (those who live in Andalucia or Extremadura) and middle income regions midreg (residents in the rest of Spain, the omitted category). The binary variable non-labour market (nonlabmkt) indicates whether the individual is not currently in the labour market (i.e. is retired, unemployed, homemaker or student) or whether s/he is. Political affiliation is recorded, by three categorical indicators, right (those who report as being centre-right, right or extreme right wing), left (those who report as being centre-left, left or extreme left wing), and centre (those who are in the political centre, the baseline category). Type is the dummy variable representing the type of question administered, taking value 1 if the $\mathrm{V}$ variant was provided, and 0 if the $\mathrm{P}$ variant was administered. Regarding the identifying variables, single, divorced and widowed are three dummy variables representing whether the individual belongs to one of such marital status (as opposed to the omitted category married); and the binary variable rural, representing whether the individual is resident in a rural area (of less than 10,000 residents). For descriptive statistics, see Table 1.

\footnotetext{
${ }^{3}$ Although it would have been desirable to derive equivalent income, this has not been possible given the available information in the survey and also given that the household income was not available as a continuous variable.
} 


\section{RESULTS}

Descriptive statistics and estimation results are reported in table 1. Overall, 69\% of full respondents chose to target the egalitarian policy. Model [eq.1] passes the Reset specification test, indicating that there is no evidence of functional form problems (table 2). In addition, when dealing with the issue of the relevance of the question variant in the model, likelihood ratio tests show that specification [eq.1] fits the data significantly better than other alternative specifications. The alternative equations considered include, on the one hand, a model that omits the type variable and, on the other hand, a model which includes the type variable together with interactions with the rest of independent variables. Therefore model [eq.1] shows that the way in which the question is presented counts, although there are no differential effects across the individual characteristics considered in the model. Item non-response leads to 514 missing cases, which corresponds to $42.5 \%$ of the entire data, leaving 695 individuals as valid cases. Estimates for the probit with sample selection [eq.2] can be seen in table 4. The correlation coefficient (rho) is not statistically different from zero. It is also true that the confidence interval for the parameter estimate is wide. However, sign, magnitude and t-ratios of coefficients of the probit with selection are very similar to those of the initial probit estimation [eq.1]. Overall, the results suggest that we cannot reject the null hypothesis that there is no selection bias.

Probit average and marginal effects evaluated at sample means (table 3) show that: firstly, other things equal, age is a statistically significant explanatory variable of the probability to target the disadvantaged group. However, the marginal effect of age on targeting is not constant and changes with the age of the respondent. For young adults between 18 and 44 the probability of targeting increases with age at a diminishing rate. A maximum is reached, on average, at the age of 44 , after which the probability of targeting starts to decrease with age at an increasing rate. Interactions between age and income or education were omitted on statistical grounds, showing that there was not a differential effect of age through different income (or education) groups.

Secondly, the existing literature suggests that female respondents will have a higher preference towards egalitarian policies, and thus, that more women will target than men. However, respondent sex did not have any statistically significant impact on the propensity to target. Thirdly, those who are politically right wing have a significantly 
lower probability of targeting the egalitarian policy, as compared to those who are in the political centre (and consequently, as compared also to those who are left wing). In particular, the probability of a right wing individual targeting is on average $12 \%$ less than the reference individual, other things being equal. Finally, living in one of the richest regions such as Madrid, Navarra or País Vasco is associated with a lower probability of targeting the egalitarian policy, other things being equal, by $17.4 \%$, compared to those living in average per capita income regions. There is no evidence that other demographic and socio-economic factors in the model have a significant influence in the attitudes towards health inequalities, including respondent sex.

Regarding the effect of the question variants, our model suggests that mode of presentation does make a difference. When individuals are administered the V-variant (as opposed to the P-variant), there is a $7 \%$ higher probability of targeting the egalitarian policy (at sample means). A comparison of this average effect with those of other variables shows that, at sample means, the average effect of the question variants is higher than that the marginal effect of age but lower than the average effect of being right wing or resident in a rich region. However, there is no evidence that the question variant has differential effects on the probability of targeting across the different demographic, socioeconomic and ideological characteristics, when these are taken jointly.

\section{DISCUSSION}

We found that a large majority of respondents (almost 70\%) chose to target the egalitarian policy. This result, while interesting, should be interpreted with care and we discuss two points here. Firstly, we deliberately did not include efficiency issues in the question in order to isolate the equity issue alone. It may be the case that there is no reason to assume that, for instance, an extra $\$ 5$ million put into program A would yield the same increase in health as the same expenditure in programme $\mathrm{B}$ and that, regardless of what the interviewers tell respondents, some of them would have made their own assumptions. In fact, the survey question of this study went on to identify the strength of inequality aversion by subjecting those respondents who choose the egalitarian policy to explicit 
trade offs between efficiency and equality ${ }^{4}$. The results are discussed in a separate paper, but they suggest that the conclusions reached in this paper would not vary substantially if we had taken into account efficiency issues (for details, see Abasolo \& Tsuchiya, 2004).

Secondly, we must be aware that the proportion of those who chose to target might be inflated by two effects. A) What could be called a "gap in life expectancy effect": in the question, the respondent is informed about current levels of health of both socioeconomic groups (70 vs 75 years). If this information had not been given to the respondent, we might have obtained a lower figure. Although this is an interesting issue that should deserve further research, it lies beyond the scope of this paper: the theoretical motivation behind the broader project that embraces the present piece of work was to estimate the inequality aversion parameter for a Health Related Social Welfare Function [Dolan, 1998], and therefore current levels of health needed to be explicit to the respondent. B) An "interviewer effect": if respondents feel that their preferences are less egalitarian than what they perceive as socially acceptable, then they may find it awkward to be seen by the interviewer not caring to target the worse off, therefore inflating the proportion of those who choose to target. The study design does not allow any explorations of this possibility, but even if it was a significant problem, insofar as they are random with respect to the determinants that we explore in this paper, conclusions would not be affected.

It should be pointed out that the main aim of the paper is not to measure the propensity to target but rather to understand how this happens. This is explored with reference to the predicted probability to target of a "standard Spaniard": an individual who is of average age (45 years old) and belongs to the baseline categories of our dummy variables, that is, male, with middle income and education levels, who is in the labour market, politically centred, resident in a middle per capita income region and has been administered the Pvariant of the question. This standard Spaniard has a $68 \%$ predicted probability of choosing the targeting policy. That is, two thirds of those with our standard features would support that resources ought to be devoted to the lowest (and unhealthiest) socio-economic group.

\footnotetext{
${ }^{4}$ Starting with the same question as the one presented in this paper, the respondents were asked four more questions in which they had to choose between the same programme A (which was invariant across the four of them) and a modified pro-poor programme B in which overall health was diminished progressively. The results show that the vast majority $(90 \%)$ of respondents, who chose B in the very first question, kept on choosing B despite the loss in efficiency.
} 
The results suggest that age has a role when explaining this (see figure 1): at age 18, the predicted probability that the standard Spaniard targets is 56\%. Starting from here, it increases with age, reaching the maximum probability of $69 \%$ at age 44 , after which this probability diminishes with additional years. This predicted profile is symmetric with respect to age so that, for example, probabilities at age $24(=44-20)$ and at age $64(=44+$ 20) are both $61 \%$. The age at which the predicted probability of targeting is $50 \%$ is age 74. The fact that the age effect was not different across income (or education) groups suggests that the targeting preference of those with below average income is not affected by their future prospects of income and social status, which contradicts the POUM hypothesis which will predict an interaction effect of age and income.

There are two possible explanations on why there may be an age effect on the propensity to target, both concerning the way age affects the way people interpret the concept "social class". The first explanation is based on "age" as a life stage. To younger people, who are yet to establish their occupation or socio-economic status, the concept of social class may have less clear connotations than to older people whose occupation and socio-economic position is well established. The second explanation is based on "age" as a proxy for cohorts. In Spain, as in other modern societies, the concept of social class is becoming more and more obsolete in daily life, so that the younger generation may find it more difficult than the older generation to see the relevance of inequalities in health across the social classes. Whilst these explanations fall short of justifying the age profile in Figure 1, they are consistent with a profile that is not a straight flat line. Given the current cross sectional dataset, it is impossible to determine whether the effect of age is a life stage effect or a cohort effect, or a mixture of both.

Those who are politically right wing have a significantly lower probability of choosing the egalitarian policy, as compared to those of the centre (and consequently as compared to those left wing). Therefore, if the standard Spaniard became right wing (other things remaining equal) this would reduce the probability of targeting by $13 \%$. This is consistent with prior expectations, that egalitarianism is associated with left wing ideology rather than right wing. However, the estimated average effect might be overestimated if, as it seems, right wing people are more reluctant to explicitly indicate their political affiliation 
in the background questions ${ }^{5}$. Finally, if a standard Spaniard was resident in one of the richest Regions like Madrid, Navarra or País Vasco (instead of living in a middle income Region) there would be, on average, a $18 \%$ lower probability of targeting the egalitarian policy. Given the decentralised Spanish health care system, regional differences in the residents' views towards health inequalities may be a matter of debate in the allocation of health care resources by regional health authorities.

Of the other demographic and socio-economic factors with possible association with respondents' propensity to target, none were statistically significantly associated. Particularly, respondent sex and socio-economic background (approximated by education and household income variables) does not seem to affect propensity to choose the egalitarian policy. Rather, health inequalities seem to be a matter of concern for the general population, irrespective of their income or education level. Taking into account that we are dealing with socio-economic inequalities in health, these results are not consistent with selfish motivations. To the contrary, they seem to have picked up the respondents playing the role as citizens facing a policy rather than the role of consumers purchasing insurance policies, which was the intention of the questionnaire.

The way in which the question is presented is associated with the probability of a given respondent choosing the egalitarian policy. People have a higher propensity to target when they deal with the verbal variant than when they face the pictorial variant. A possible explanation for this is that the pictorial variant may have emphasised the gain more than the existing inequality. As was discussed under the effect of respondent sex, contrary to the consequentialist economist' conceptualisation, programme $\mathrm{A}$, which gives equal amounts to both groups, might be perceived by the lay respondent as being more equal than programme $\mathrm{B}$, which gives nothing to one group an all the benefits to the other. The illustrated P-variant seems to be at a higher risk of this happening, because it visualises the differences across the two programmes in terms of what the two population groups will gain. The current baseline inequality is the same across the two programmes, so they could be cancelled out from the cognitive process. Should this happen, then those respondents who, had they been given the V-variant may have chosen to target, may well

\footnotetext{
${ }^{5}$ Only $21 \%$ of individuals report that they are centre-right or right, whilst $47 \%$ of respondents report a centre-left or left ideology. In 1999, the Spanish Popular Party was in government (a centre-right party) and
} 
choose not to target in the $\mathrm{P}$-variant precisely because they regard themselves as egalitarian. Although the current data do not lead us to discriminate in favour of one particular mode of administration, we believe that this issue deserves more research in order to explore the reasons that lead people to choose differently under these two different formats.

It should also be noted that, despite this variant effect, the overall proportion of respondents who chose to target is roughly the same across the two questionnaire variants and the difference is not statistically significant (64\% vs 69\%). In certain research contexts, where the aim of the study is not to explain the variation in targeting behaviour by respondent background characteristics, this may be seen as sufficient justification to pool the data from the two variants.

\section{CONCLUSION}

The impact of demographic characteristics has been largely investigated in the literature as motivations on people's attitudes over justice and rights in general and over income inequalities in particular. However, this has not been the case when we tackle attitudes towards redistributive or egalitarian policies in the health field. Stronger female traits towards solidarity observed in other areas was not observed in our example based on redistributive policies in health: respondent sex does not seem to have a significant impact when choosing egalitarian policies. On the other hand, results regarding respondent age suggest, in line with previous studies, changing levels of tolerance with aging towards socioeconomic health inequalities, but not lineally, so that younger and older individuals are significantly less likely to support egalitarian policies compared to middle age individuals. Analysis of other factors that have been controlled for show that right-wingers and/or those living in affluent regions are significantly less likely to support egalitarian policies; unexpectedly, other socioeconomic background characteristics such as individual's education or household's income do not seem to have a significant impact. The evidence also shows that the way in which the question is administered also counts: the regression results indicate that on average, there is a significantly higher probability to target when people deal with numbers rather than with pictures.

the survey was undertaken just 3 months before general elections which the Popular Party won again with absolute majority. 


\section{REFERENCES}

Abásolo I., Shaw R., Tsuchiya A. (2001) ¿Hasta qué punto están más preocupados los españoles por la equidad que por la eficiencia en salud? Comunicación presentada en las XXI Jornadas de la Asociación de la Economía de la Salud, 6-8 June, Oviedo.

Abásolo I., Tsuchiya, A. (2004) Exploring Social Welfare Functions and violation of monotonicity: An example from inequalities in health. Journal of Health Economics, 23 (2): $313-329$.

Acheson D. (1998) Independent Inquiry into Inequalities in health. London, HMSO.

Andersson F., Lyttkens CH. (1999). Preferences for equity in health behind a veil of ignorance. Health Economics;8(5):369-78.

Bénabou R. and Ok E. (2001) Social mobility and the demand for redistribution: the POUM hypothesis. Quarterly Journal of Economics, 116 (2): 447-487.

Beutel A., Marini M. (1995) Gender and values, American Sociological Review, 60: 436448.

Borrell C., Regidor E., Arias L. (1999) Inequalities in mortality according to educational level in two large southern European cities. International Epidemiological Association, 28: 58-63.

Cuadras-Morato X, Pinto-Prades JL, Abellán-Perpiñan JM (2001). Equity considerations in health care: The relevance of claims. Health Economics;10(3):187-205.

Davies M. (1983) The effect of dispositional empathy on emotional reactions and helping: a multi-dimensional approach, Journal of Personality, 51: 167-184. 
Dolan P. (1998) The measurement of individual utility and social welfare. Journal of Health Economics.17:39-52.

Dolan P., Robinson A (2001). The measurement of preferences over the distribution of benefits: The importance of the reference point. European Economic Review;45(9):1697709.

Dolan P, Tsuchiya A, Smith P, Shaw R, Williams A. (2002) Determining the parameters in a social welfare function using stated preference data: an application to health. Sheffield Health Economics Study Group, University of Sheffield. Discussion Paper Series $02 / 2$.

Eckel C., Grossman P.J. (1998) Are women less selfish than men?: evidence from dictator experiments, The Economic Journal, 108 (May): 726-735.

Fehr E., Fischbacher U. (2002) Why social preference matter -the impact of non-selfish motives on competition, cooperation and incentives. The Economic Journal, 112: C1-C33.

Fong Ch. (2001) Social preferences, self-interest, and the demand for redistribution. Journal of Public Economics, 82: 225-246.

Gilligan C. (1983) In a different voice. Harvard University Press.

Greene WH (1997) Econometric Analysis. Prentice Hall, third edition. New Jersey.

Hudson J. and Jones P. (2002) In search of the good Samaritan: estimating the impact of ‘altruism' on voter's preferences. Applied Economics, 34: 377-383.

Jaffee S. and Hyde J.S. (2000) Gender differences in moral orientation: a meta-analysis, Psychological Bulletin, 126(5): 703-726. 
Johannesson M, Gerdtham UG (1996). A note on the estimation of the equity-efficiency trade-off for QALYs. Journal of Health Economics;15:359-368.

Kitchen H. and Dalton R. (1990) Determinants of charitable donations by families in Canada: a regional analysis. Applied Economics, 22: 285-299.

Kitchen H. (1992) Determinants of charitable donations in Canada: a comparison over time. Applied Economics, 24: 709-713.

Lindholm, L., Emelli, M., Rosén, M. (1997) Health maximization rejected -the view of Swedish health care politicians. European Journal of Public Health; 7: 405-10.

Meltzer A., Richards S. (1981) A rational theory of the size of government. Journal of Political Economy, 89: 914-927.

Ohtake F. and Tomioka J. (2004) Who supports redistribution? The Japanese Economic Review, 55 (4): 333-354.

Romer T. (1975) Individual welfare, majority voting and the properties of a linear income tax. Journal of Public Economics, 7: 163-188.

Shapiro R., Hanajan H. (1986) Gender differences in policy preferences: a summary of trends from the 1960s to the 1980s, Public Opinion Quarterly, 50: 42-61.

Wagstaff A (1994). QALYs and the equity-efficiency tradeoff. In: Layard A, Glaister S, eds. Cost-Benefit Analysis. second edition: Cambridge University Press (reprinted from Journal of Health Economics, 10:21-41, 1991 with corrections)

Williams A (1997). Intergenerational equity: an exploration of the 'fair innings' argument. Health Economics 6: 117-132

\section{Acknowledgements}


We would like to thank Juan Diez-Nicolas, Paul Dolan, Roberto Gonzalez, Andrew Jones, Jaime Pinilla, Rebecca Shaw, Alan Williams, and the anonymous referee and the editor of Applied Economics for their input. We are also grateful to all the respondents who agreed to take part in the survey, and to the Spanish Instituto de Estudios Fiscales for financial support to undertake this research. The usual disclaimers apply. 
OPTIONS PRESENTED IN THE PICTORIAL VERSION (P)

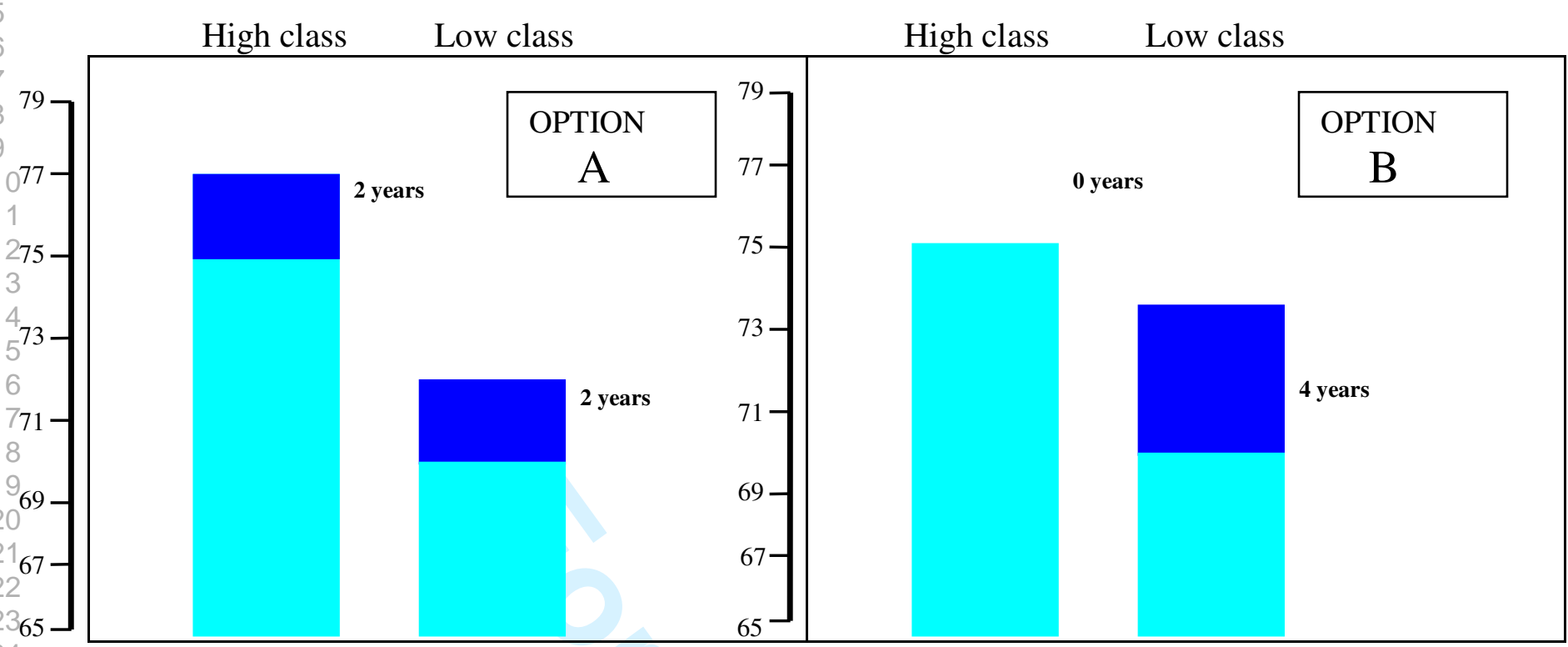

\section{OPTIONS PRESENTED IN THE VERBAL VERSION (V)}

\begin{tabular}{|l|c|}
\hline $\begin{array}{l}\text { Increase high class life expectancy in } 2 \text { years and low class life expectancy in } 2 \text { years. } \\
\text { The final outcome of life expectancy would be: } \\
\text { high class: } 77 \text { years } \\
\text { low class: } 72 \text { years }\end{array}$ & $\begin{array}{c}\text { OPTION } \\
\text { A }\end{array}$ \\
\hline $\begin{array}{l}\text { Increase only low class life expectancy. } \\
\text { The final outcome of life expectancy would be: } \\
\text { high class: } 75 \text { years } \\
\text { low class: } 74 \text { years }\end{array}$ & OPTION \\
\end{tabular}


Figure 1: Probability of chosing the "egalitarian" option of a standard Spaniard; by respondent age

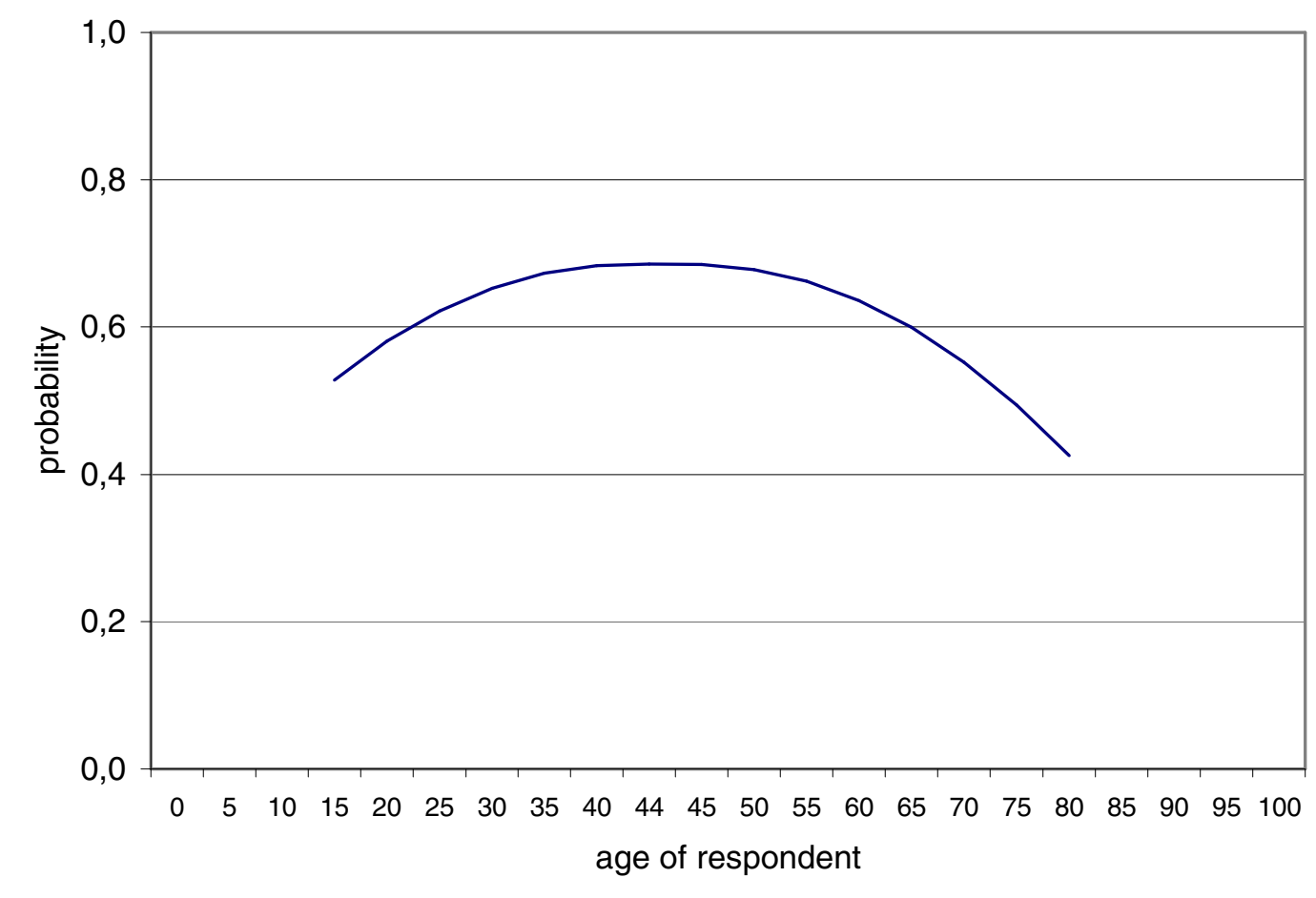


TABLE 1. MEAN VALUES AND STANDARD DEVIATIONS OF VARIABLES

\begin{tabular}{|ccccrr|}
\hline VARIABLE & OBS & MEAN & STD.DEV & MIN & MAX \\
\hline Target & 695 & .6904674 & .4626339 & 0 & 1 \\
\hline Female & 695 & .485911 & .5001614 & 0 & 1 \\
\hline Age & 695 & 45.26725 & 17.5467 & 18 & 91 \\
\hline Agesq & 695 & 2356.567 & 1709.339 & 324 & 8281 \\
\hline Highedu & 695 & .2362348 & .425074 & 0 & 1 \\
\hline Midedu & 695 & .4139528 & .492895 & 0 & 1 \\
\hline Lowedu & 695 & .3498124 & .477254 & 0 & 1 \\
\hline Highinc & 695 & .2259842 & .4185301 & 0 & 1 \\
\hline Midinc & 695 & .4759503 & .499781 & 0 & 1 \\
\hline Lowinc & 695 & .2980655 & .4577378 & 0 & 1 \\
\hline Nonlabmkt & 695 & .5352979 & .4991117 & 0 & 1 \\
\hline Left & 695 & .4718532 & .4995667 & 0 & 1 \\
\hline Centre & 695 & .5377811 & .4989296 & 0 & 1 \\
\hline Right & 695 & .2190156 & .4138771 & 0 & 1 \\
\hline Reghigh & 695 & .1453269 & .352684 & 0 & 1 \\
\hline Regmid & 695 & .299272 & .4582689 & 0 & 1 \\
\hline Reglow & 695 & .223194 & .4166872 & 0 & 1 \\
\hline Type & 695 & .5006595 & .5003597 & 0 & 1 \\
\hline Single & 695 & .2614786 & .4397565 & 0 & 1 \\
\hline Divorced & 695 & .0256607 & .1582349 & 0 & 1 \\
\hline Married & 695 & .6236525 & .4848178 & 0 & 1 \\
\hline Widowed & 695 & .0892082 & .2852493 & 0 & 1 \\
\hline Rural & 695 & .2762375 & .4474578 & 0 & 1 \\
\hline
\end{tabular}


TABLE 2. RESULTS PROBIT ESTIMATION

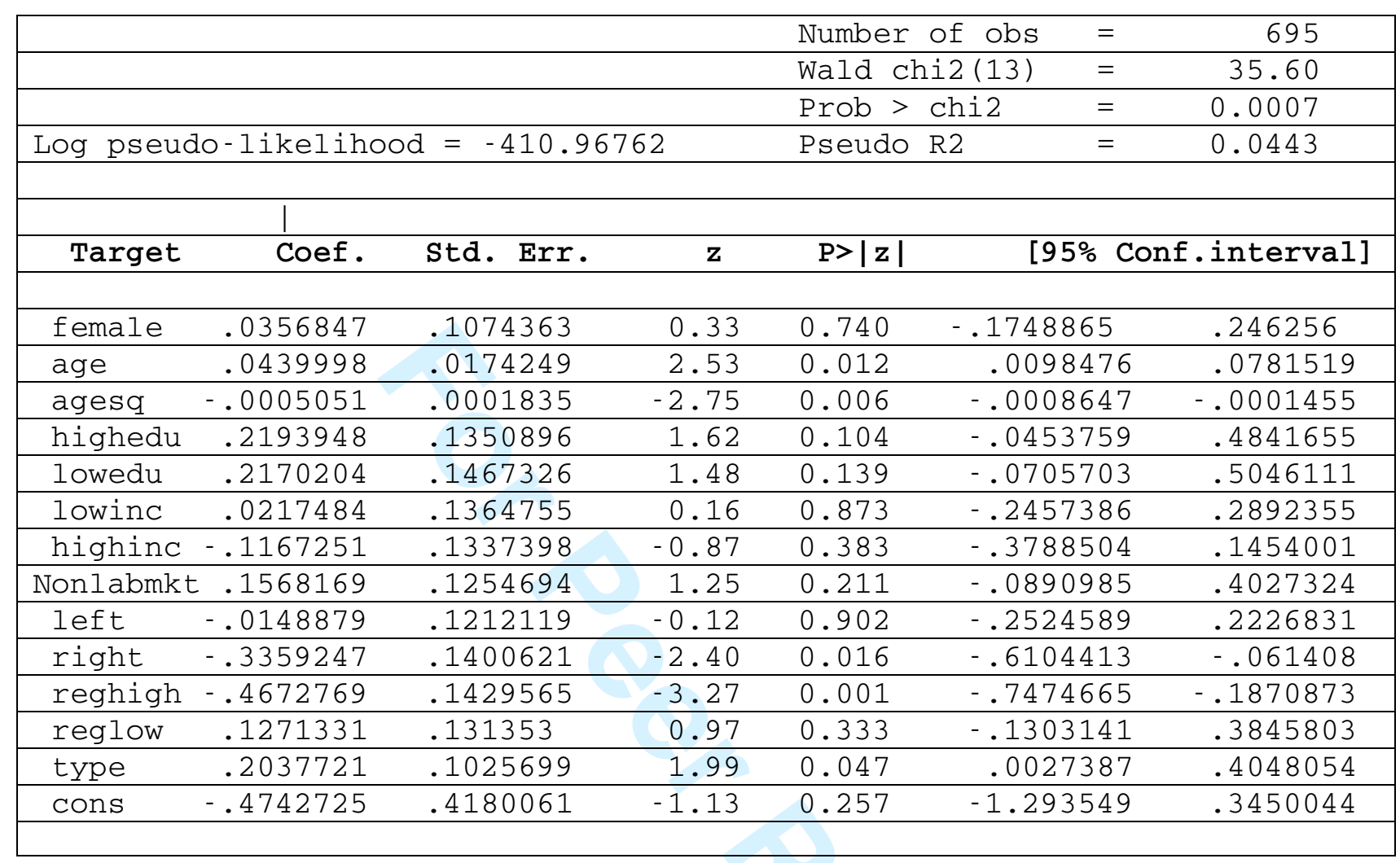

RESET TEST

\begin{tabular}{|ll|}
\hline . test targetf $2=0$ \\
\hline chi2 $(1)=0.30$ \\
\hline Prob $>$ chi2 $=0.5835$ \\
\hline
\end{tabular}


TABLE 3. PROBIT MARGINAL AND AVERAGE EFFECTS

\begin{tabular}{|c|c|c|c|c|c|c|}
\hline & & & & \multicolumn{3}{|c|}{ Number of obs $=695$} \\
\hline & & & & \multicolumn{3}{|c|}{ Wald chi2 $(13)=35.60$} \\
\hline & & & & \multicolumn{2}{|c|}{ Prob > chi2 } & $=0.0007$ \\
\hline \multicolumn{4}{|c|}{ Log pseudo-likelihood $=-410.96762$} & Pseudo $\mathrm{R}$ & $=0$. & 0443 \\
\hline target & std. Err. & $\mathbf{z}$ & $\mathrm{P}>|\mathbf{z}|$ & \multicolumn{2}{|l|}{$\mathrm{x}$-bar } & {$[95 \%$ C.I.] } \\
\hline .0124443 & .0374514 & 0.33 & 0.740 & .485911 & -.060959 & .085848 \\
\hline .0153486 & .0060819 & 2.53 & 0.012 & 45.2672 & .003428 & .027269 \\
\hline-.0001762 & .000064 & -2.75 & 0.006 & 2356.57 & -.000302 & .000051 \\
\hline .0740483 & .0439303 & 1.62 & 0.104 & .236235 & -.012053 & .16015 \\
\hline .0742953 & .0491645 & 1.48 & 0.139 & .349812 & -.022065 & .170656 \\
\hline-.041359 & .0480767 & -0.87 & 0.383 & .225984 & -.135588 & .05287 \\
\hline lowinc* $\quad .0075692$ & .0473876 & 0.16 & 0.873 & .298065 & -.085309 & .100447 \\
\hline nonlab t* .054818 & .0438967 & 1.25 & 0.211 & .535298 & -.031218 & .140854 \\
\hline left* $\quad-.0051945$ & .042302 & -0.12 & 0.902 & .471853 & -.088105 & .077716 \\
\hline-.1220372 & .0525067 & -2.40 & 0.016 & .219016 & -.224948 & -.019126 \\
\hline reghigh* -.1738084 & .0553471 & -3.27 & 0.001 & .145327 & -.282287 & -.06533 \\
\hline .0434998 & .0440084 & 0.97 & 0.333 & .223194 & -.042755 & .129755 \\
\hline .0709977 & .0355512 & 1.99 & 0.047 & .50066 & .001319 & .140677 \\
\hline .6904674 & & & & & & \\
\hline .6978101 & (at $\mathrm{x}$-bar) & & 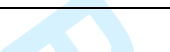 & & & \\
\hline $\begin{array}{l}\text { (*) } \mathrm{dF} / \mathrm{dx} \text { is for } \mathrm{di} \\
\mathrm{z} \text { and } \mathrm{P}>|\mathrm{z}| \text { are }\end{array}$ & $\begin{array}{l}\text { Crete cha } \\
\text { the test }\end{array}$ & $\begin{array}{l}\text { ge oI } \\
\text { f the }\end{array}$ & derly & $\begin{array}{l}\text { able } f r \\
\text { coeffi }\end{array}$ & $\begin{array}{l}0 \text { to } 1 \\
\text { ent being }\end{array}$ & 0 \\
\hline
\end{tabular}




\section{TABLE 4. PROBIT WITH SAMPLE SELECTION}

\begin{tabular}{|c|c|c|c|c|c|c|}
\hline & & & \multicolumn{3}{|c|}{ Number of obs } & 1209 \\
\hline & & & \multicolumn{3}{|c|}{ Censored obs } & 514 \\
\hline & & & \multicolumn{3}{|c|}{ Uncensored obs } & 695 \\
\hline & & & \multicolumn{3}{|c|}{ Wald chi2(13) } & 38.00 \\
\hline \multicolumn{3}{|c|}{ Log likelihood $=-1205.962$} & \multicolumn{3}{|c|}{ Prob > chi2 } & 0.0003 \\
\hline & Coef. & Std. Err. & \multicolumn{2}{|c|}{$\mathrm{P}>|\mathrm{z}|$} & {$[95 \%$ Conf. } & Interval] \\
\hline \multicolumn{7}{|l|}{ target } \\
\hline female & .0057774 & .1480517 & 0.04 & 0.969 & -.2843986 & .2959535 \\
\hline age & .0489134 & .0217279 & 2.25 & 0.024 & .0063275 & .0914993 \\
\hline agesq & -.0005496 & .000214 & -2.57 & 0.010 & -.0009691 & -.0001302 \\
\hline highedu & .2097602 & .1384156 & 1.52 & 0.130 & -.0615294 & .4810498 \\
\hline lowedu & .2111436 & .1451737 & 1.45 & 0.146 & -.0733917 & .4956788 \\
\hline highinc & -.1141935 & .1327207 & -0.86 & 0.390 & -.3743213 & .1459344 \\
\hline lowinc & .0226788 & .1338767 & 0.17 & 0.865 & -.2397148 & .2850724 \\
\hline nonlabmkt & .1352117 & .1500073 & 0.90 & 0.367 & -.1587973 & .4292207 \\
\hline left & -.0149317 & .1195964 & -0.12 & 0.901 & -.2493362 & .2194729 \\
\hline right & -.3305266 & .1424466 & -2.32 & 0.020 & -.6097169 & -.0513364 \\
\hline reghigh & -.534301 & .2321364 & -2.30 & 0.021 & -.9892799 & -.079322 \\
\hline reglow & .1492482 & .1469055 & 1.02 & 0.310 & -.1386813 & .4371778 \\
\hline type & .2003553 & .1029275 & 1.95 & 0.052 & -.0013789 & .4020895 \\
\hline Cons & -.7403945 & .9407209 & -0.79 & 0.431 & -2.584174 & 1.103385 \\
\hline \multicolumn{7}{|l|}{$\mathbf{z}$} \\
\hline female & -.2007844 & .0792574 & -2.53 & 0.011 & -.356126 & -.0454427 \\
\hline age & .0364361 & .0136711 & 2.67 & 0.008 & .0096411 & .063231 \\
\hline agesq & -.0003817 & .0001372 & -2.78 & 0.005 & -.0006505 & -.0001129 \\
\hline nonlabmkt & -.0980364 & .088269 & -1.11 & 0.267 & -.2710405 & .0749677 \\
\hline reghigh & -.4232526 & .0963924 & -4.39 & 0.000 & -.6121783 & -.2343269 \\
\hline reglow & .1806764 & .0976276 & 1.85 & 0.064 & -.0106701 & .372023 \\
\hline single & -.1022373 & .1099509 & -0.93 & 0.352 & -.317737 & .1132624 \\
\hline divorced & -.1270649 & .2394361 & -0.53 & 0.596 & -.596351 & .3422211 \\
\hline widowed & .2583478 & .152567 & 1.69 & 0.090 & -.0406781 & .5573737 \\
\hline rural & .1091552 & .0928946 & 1.18 & 0.240 & -.0729148 & .2912253 \\
\hline _cons & -.3541731 & .3366173 & -1.05 & 0.293 & -1.013931 & .3055846 \\
\hline athrho & .2713856 & .9422376 & 0.29 & 0.773 & -1.575366 & 2.118137 \\
\hline rho & .2649136 & .876112 & & & -.9178751 & .9714896 \\
\hline LR test of & ndep. eqn & $($ rho $=0)$ & chi2l & $=0.0$ & Prob $>\mathrm{Ch}$ & $=0.7742$ \\
\hline
\end{tabular}

